\title{
PENERAPAN BUDAYA JEPANG (SEIRI DAN SEITON) TERHADAP PRODUKTIVITAS KERJA PADA KARYAWAN R\&D PT. HIT
}

\author{
Bun Norikun $^{1 *}$, \\ Yulina M.N ${ }^{1}$, Ardi Novianto ${ }^{2}$, Surya Purba $W^{3}$, Enik Sukendri ${ }^{4}$, Nailis Sa'adah ${ }^{5}$, Tomy \\ Fitrianto $^{6}$, Riana Sari Ayunani ${ }^{7}$, Bambang Sriyanto ${ }^{8}$, Antonius Fransiskus ${ }^{9}$, Junaidi ${ }^{10}$, \\ Rif' an $^{11}$, Rully Septiadi ${ }^{12}$, Akhmad Hudayana ${ }^{13}$, Puji Astuti ${ }^{14}$, Devi Setyawan ${ }^{15}$, Leli \\ Setiana Dewi ${ }^{16}$, Arwan $^{17}$, Indra Danang D.A. ${ }^{18}$, M. Hendris Norsriana ${ }^{19}$, Jeffa Aska \\ Riyandi $^{20}$
}

\begin{abstract}
Abstrak
Penelitian ini bertujuan untuk mengetahui pengaruh 5R dari seiri dan seiton dalam mempengaruhi produktifitas kerja, serta untuk mengetahui adanya korelasi antara Seiri dan Seiton dengan produktifitas kerja. Sampel pada penelitian ini adalah karyawan R\&D PT. HIT dengan teknik purposive sampling sebanyak 82 responden. Teknik analisis yang dipergunakan adalah korelasi dan regresi linier berganda dengan SPSS.

Kesimpulan yang di dapat dari pengujian bahwa seiri belum dapat memberikan pengaruh signifikan terhadap peningkatan produktivitas kerja karyawan, seiton memberikan pengaruh signifikan terhadap peningkatan produktifitas kerja.
\end{abstract}

Kata Kunci : 5R Seiri dan Seiton, Produktivitas Kerja

\section{PENDAHULUAN}

Pegawai sebagai individu dalam sebuah organisasi merupakan bagian terpenting, karena peran besar dalam menentuan keberhasilan pencapaian tujuan organisasi. Peran pegawai sebagai asset organisasi yang dibutuhkan untuk memaksimalkan kinerja, produkstivitas, maupun efektivitas organisasi melalui cara kerja efesien sehingga menghasilkan nilai tambah bagi organisasi. Produktifitas suatu organisasi, tidak terlepas dari kinerja para anggota organisasi. Produktivitas merupakan suatu cara untuk mendeteksi kemajuan suatu perusahaan, dengan membandingkan jumlah produksi sebagai keluaran (output) dengan jumlah tenaga kerja sebagai masukan atau input (Abidin, 2018).

Budaya Jepang yang sangat terkenal dengan kaizen. Keizen berasal dari bahasa Jepang pada konsep Continous Incremental Improvement. Kai yang memiliki arti perubahan dan Zen memiliki arti baik. Kaixen yaitu penyempurnaan dan berkesinambungan yang mana melibatkan semua orang. Kaizen merupakan suatu

*Corresponding author. 
kesatuan pandangan yang yang komprehensif dan terintegrasi yang bertujuan untuk melaksanakan perbaikan secara terus-menerus.

PT. Hartono Istana Teknologi adalah perusahaan manufaktur elektronik yang beralamat di Kudus. Departemen RnD merupakan pilar penting dalam Manufaktur, yang tugas utamanya adalah menghasilkan produk-produk unggulan melalui inovasi produk dengan target waktu development yang telah ditentukan sehingga launching produk menjadi tepat waktu. Menunjang proses kerja $\mathrm{RnD}$ untuk menghasilkan produk bermutu, efisien, tepat waktu (Q-D-C) dengan didukung oleh lingkungan kerja yang aman, nyaman, sehat dan rapi. Dengan demikian perusahaan berusaha memenuhi kebutuhan akan pemenuhan kebutuhan tenaga kerja yang kompeten. Program 5R (Ringkas, Rapi, Resik, Rawat, Rajin) merupakan adaptasi dari 5S (Seiri, Seiton, Seiso, Seiketsu, Shitsuke) yang dikembangkan di Jepang oleh Hiroyuki Hirano dan sudah digunakan oleh banyak negara diseluruh penjuru dunia (Sartono dam Mukhamad, 2012). Ini merupakan suatu metode sederhana untuk melakukan penataan dan pembersihan tempat kerja yang dikembangkan dan diterapkan di Jepang.

\section{TELAAH PUSTAKA}

\section{S atau $5 R$}

5S merupakan budaya seseorang dalam memperlakukan tempat kerjanya secara benar, memelihara dan menjaga tempat kerja agar tertata rapi, bersih dan tertib sehingga kemudahan dalam bekerja dapat diciptakan. 5S terdiri dari Seiri, Seiton, Seiso, Seiketsu, Shitsuke (Rinandiyanaa dan Yanyan 2015).

Menurut Osada (2000:31) dalam Rinandiyanaa dan Yanyan (2015) tujuan dari $5 \mathrm{~S}$ adalah sebagai berikut:

a. Keamanan

Selama puluhan tahun, kedua kata pemilahan dan penataan menjadi cirri khas yang menyolok pada poster-poster dan surat kabar bahkan di perusahaanperusahaan kecil. Karena keamanan sangat penting, dan sebaliknya pemilahan dan penataan sangat penting untuk keamanan.

b. Tempat Kerja yang Rapih

Tempat kerja yang menerapkan 5S dengan teliti tidak perlu terus-menerus membicarakan keamanan, dan kecelakaan industri yang dialaminya akan lebih 
sedikit ketimbang pabrik yang hanya mengutamakan peralatan dan prosedur yang sedemikian aman sehingga tidak mungkin gagal.

c. Efisiensi

Para ahli diberbagai bidang seperti, juru masak, pelukis, tukang kayu. Mereka menggunakan peralatan yang baik dan mereka memeliharanya. Mereka tahu bahwa waktu yang dipergunakan untuk memelihara peralatan tidak terbuang percuma, bahkan hal itu menghemat lebih banyak waktu.

d. Mutu

Elektronika modern dan mesin lain memerlukan tingkat presisi dan keberhasilan yang sangat tinggi, untuk menghasilkan output yang baik. Berbagai gangguan yang kecil dapat berakibat terhadap penurunan mutu dari output yang dihasilkan.

e. Kemacetan

Pabrik yang tidak menerapkan 5R akan menghadapi berbagai masalah kemacetan mulai dari mesin yang disebabkan kotoran mengendap ataupun kemacetan dalam kepala karyawan, harus kita sadari bahwa ingatan seseorang bisa saja salah, maka daripada itu diperlukan berbagai petunjuk yang melengkapi keterbatasan seorang manusia dalam menjalankan tugasnya.

\section{Produktivitas}

Produktivitas kerja merupakan kemampuan dari karyawan untuk memperoleh manfaat yang sebesar besarnya dari sarana dan prasarana yang tersedia dengan menghasilkan output yang optimal. Sutrisno, (2016:102) menyatakan bahwa produktivitas adalah perbandingan antara hasil yang dicapai dengan peran serta tenaga kerja persatuan waktu. Produktivitas juga mempunyai aspek sebagai berikut :

1. Produktivitas adalah keluaran fisik per unit dari usaha produktif.

2. Produktivitas merupakan tingkat keefektifan dari manajemen industry di dalam penggunaan fasilitas-fasilitas untuk produksi.

3. Produktifitas adalah keefektifan dari penggunaan tenaga kerja dan peralatan.

Produktivitas tenaga kerja dapat digambarkan dengan rumus yang berarti perbandingan dengan hasil yang dicapai (output) dengan keseluruhan sumber daya yang digunakan (input). Atau di definisikan sebagai indek produktivitas yaitu :

$$
\text { IP }=\frac{\text { Hasil yang dicapai }}{\text { Sumber daya yang digunakan }}=\frac{\text { Output }}{\text { Input }}
$$




\section{Seiri (Ringkas)}

Ringkas adalah membuang apa yang tidak dibutuhkan dan membersihkan tempat kerja (Veres, et al. 2018). Wahyudi (2017) juga menyatakan 5S Seiri berarti membedakan antara yang diperlukan dengan yang tidak diperlukan, mengambil keputusan yang tegas dan menerapkan manajemen stratifikasi (skala urutan atau prioritas). Jadi ringkas merupakan memilah atau membedakan antara yang diperlukan dan tidak diperlukan dan menyingkirkan yang tak diperlukan. Hal ini dapat diterapkan dengan melakukan manajemen stratifikasi yaitu menurut diagram pareto dan metode KJ adalah merupakan alat kendali mutu standar yang dipergunakan untuk memecahkan masalah dan memprioritaskan masalah serta memilah informasi.

Pada diagram pareto dan metode $\mathrm{KJ}$ (dinamai diagram pareto dan metode $\mathrm{KJ}$ adalah sesuai dengan nama Vilfredo Pareto dan Jiro Kawakita) adalah alat ukur mutu standar yang dipergunakan dalam memecahkan masalah dan memprioritaskan serta memilah informasi (Takashi Osada, 1995:24) dalam Wahyudi (2017) dapat dilakukan dengan membuat daftar persediaan barang-barang (peralatan) (cara untuk menyusun barang-barang (peralatan), memutuskan mana yang penting dan mana yang sangat penting) kemudian menyiapkan manajemen stratifikasi berdasarkan prioritas, membuang barang-barang (peralatan) persediaan yang kurang laku atau membuat perubahan berkala sesuai permintaan, merupakan cara lain untuk memindahkan atau membuang barang-barang (peralatan) yang kurang diperlukan atau membedakan antara yang penting dan tidak penting di tempat kerja.

Gambar 1 : Proses kegiatan Pemilahan (Seiri)

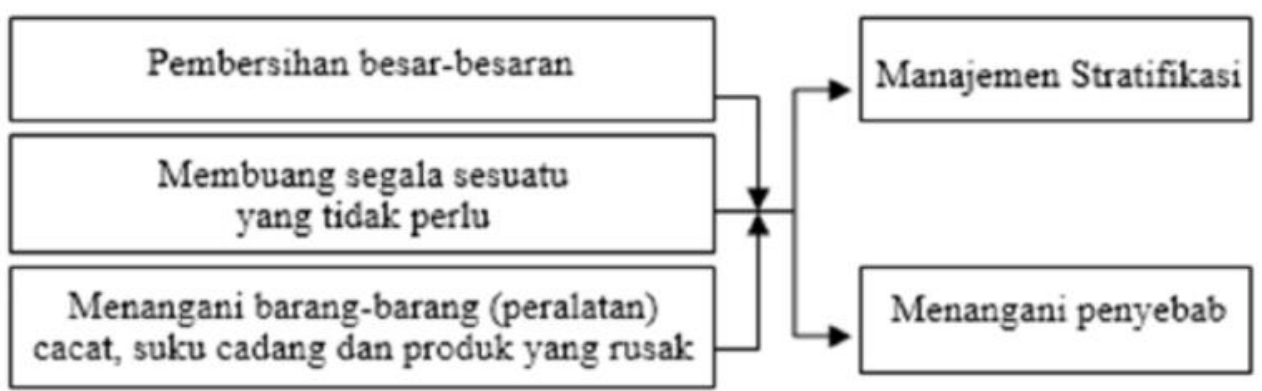


Tabel 1 : Menyimpan Barang-barang (peralatan) Yang Diperlukan

\begin{tabular}{|c|l|l|}
\hline No. & \multicolumn{1}{|c|}{ Barang-barang (Peralatan) } & \multicolumn{1}{|c|}{ Penyimpanan } \\
\hline 1 & $\begin{array}{l}\text { Barang-barang (peralatan) yang } \\
\text { sering digunakan }\end{array}$ & $\begin{array}{l}\text { Simpan ditempat yang mudah di } \\
\text { jangkau }\end{array}$ \\
\hline 2 & $\begin{array}{l}\text { Barang-barang (peralatan) yang selalu } \\
\text { digunakan }\end{array}$ & $\begin{array}{l}\text { Simpan supaya mudah diambil, } \\
\text { mudah disimpan, dan mudah } \\
\text { dipahami dimana harus disimpan. }\end{array}$ \\
\hline 3 & $\begin{array}{l}\text { Barang-barang (peralatan) yang } \\
\text { kadang-kadang digunakan }\end{array}$ & $\begin{array}{l}\text { Pastikan untuk menyimpan kembali } \\
\text { di tempat semula yang berarti harus } \\
\text { ada sebuah papan bergambar, kode } \\
\text { warna, label, dll. }\end{array}$ \\
\hline 4 & Arsip & $\begin{array}{l}\text { Beri label, nomor, dan kode warna } \\
\text { baik pad arak, outner, maupun kode } \\
\text { penjilitan. }\end{array}$ \\
\hline
\end{tabular}

Jadi pada proses Seiri (pemilahan) hal yang perlu dilakukan adalah melakukan pemilahan dan menyimpan barang-barang (peralatan) di tempat yang semestinya, hal ini merupakan prioritas tertinggi pada kegiatan 5S (Seiri, Seiton, Seiso, Seiketsu, Shitsuke) lainnya karena pada kegiatan pemilahan ini karyawan sebagai individu umumnya sedemikian sibuk dengan pekerjaannya atau sedemikian terbiasa mengerjakan sesuatu sehingga ia tidak menyadari perlunya kegiatan pemilahan, kondisi seperti ini harus ada usaha yang berulang-ulang dan terus menerus untuk membuang barang-barang (peralatan) yang tidak diperlukan karena sangat sulit untuk membuang segala sesuatu sekaligus. Kegiatan seiri ini perlu dilakukan kampanye secara terus menerus untuk mendidik karyawan di tempat kerja guna melaksanakan penyempurnaan dan memeriksa hasilnya dan melakukan lebih banyak perbaikan yang berkelanjutan.

\section{Seiton (Rapi)}

Rapi adalah merapikan atau menata semua barang yang ada setelah ringkas, setiap barang memiliki tempat dengan pola yang teratur dan tertib. Veles, et al. (2017) juga menyatakan rapi adalah mempersiapkan barang-barang yang diperlukan dengan rapi dan sistematis sehingga dapat dengan mudah diambil dan dikembalikan ke tempat semula setelah digunakan.

Indosdm (2008) dalam Wahyudi (2017) menjelaskan mengenai prosedur dasar untuk melakukan penataan terhadap penyimpanan barang-barang (peralatan) sehingga dapat dilakukan suatu upaya sebagai berikut : 
a. Melakukan analisis kenyataan (analisis status quo) yaitu : Suatu penataan yang melakukan pengkajian secara efisiensi. Bentuk pengkajian tersebut adalah seberapa cepat barang-barang (peralatan) dapat ditemukan saat dipergunakan dan disimpan kembali setelah selesai digunakan.

b. Tentukan tempatnya yang tepat yaitu : Menentukan tempat ini sangat penting karena dapat melakukan stratifikasi terhadap penggunaan barang-barang (peralatan) sehingga barang-barang (peralatan) yang sering dipakai lebih baik disimpan di dekat pintu sedangkan barang-barang (peralatan) yang berat harus ditempatkan sedemikian rupa sehingga dapat dipindahkan dengan mudah.

c. Tentukan bagaimana seharusnya menyimpan barang-barang (peralatan) yaitu : Penyimpanan fungsional merupakan penyimpanan yang tentu saja dilakukan dengan mempertimbangkan mutu (produk), keamanan (untuk menjaga dan menghindari adanya kekeliruan terhadap barang-barang (peralatan) yang mirip atau yang hampir sejenis) dan efisiensi (agar barang-barang (peralatan) yang dibutuhkan ditempatkan di tempat yang paling dekat dengan penggunaannya), seluruh proses tersebut dalam penyimpanan barang-barang (peralatan) bertujuan untuk memperlancar pekerjaan karena bila setiap barang-barang (peralatan) memiliki tempat dan ada ditempatnya masing-masing hal ini akan mengurangi kekeliruan dan pekerjaan akan menjadi lebih lancar serta mempermudah pekerjaan yang segera akan dimulai.

d. Ajarkan setiap orang untuk mentaati aturan penyimpanannya yaitu : Dimaksudkan agar orang yang mengambil dan menggunakan barang-barang (peralatan) jika selesai penggunaannya maka barang-barang (peralatan) tersebut harus dikembalikan ke tempat penyimpanan semula sehingga ketika barangbarang (peralatan) tersebut dibutuhkan kembali ada ditempatnya.

Untuk lebih jelasnya mengenai kegiatan seiton (penataan) dapat dilihat pada gambar dibawah ini mengenai promosi penataan. 
Gambar 2 : Proses kegiatan Pemilahan (Seiri)

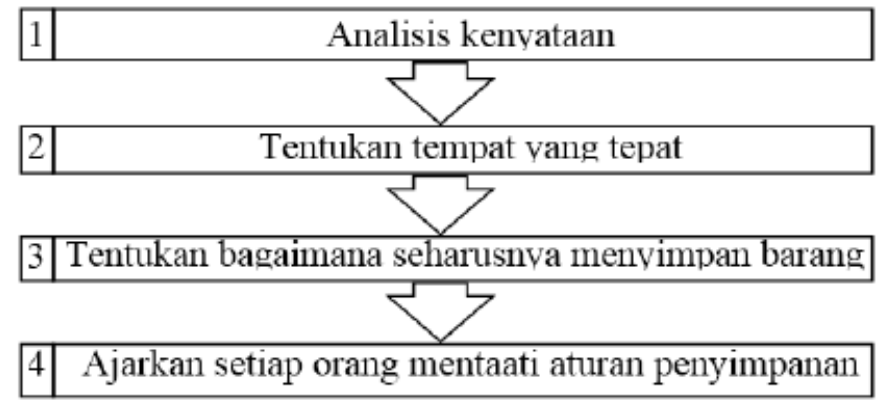

Pengetahuan dasar budaya kerja 5S memberikan uraian mengenai kegiatan untuk mencari barang-barang (peralatan) pada kegiatan seiton (penataan), sehingga kegiatan tersebut harus diketahui terlebih dahulu prosedur untuk mencari barangbarang (peralatan) dapat dibagi menjadi 7 (tujuh) langkah yaitu sebagai berikut :

a. Buanglah segala sesuatu yang tidak berguna yaitu mengikuti fakta-fakta penting yang telah dijelaskan sebelumnya dalam topik seiri.

b. Bersihkan rak-rak penyimpanan yaitu penggunaan ruang untuk rak dan tempat penyimpanan file yang telah ditetapkan dalam bagian seiri harus di-sub kelompokkan kembali. Selain itu rak tambahan dibuat seminim mungkin dengan mempertimbangkan adanya kebutuhan dan pengaturan yang tepat.

c. Tentukan tempat penyimpanan yaitu mengatur pertemuan untuk menentukan cara menyimpan yang mudah dan sederhana dengan mempertimbangkan beberapa hal berikut:

- Barang-barang (peralatan) yang sering dipakai harus disimpan di dekat pengguna.

- Barang-barang (peralatan) yang sering dipakai harus disimpan di tempat setinggi antara bagian siku dan bahu.

- Barang-barang (peralatan) yang jarang dipakai harus disimpan di tempat lain dengan membedakannya menurut penggunaan (kumpulkan semua barangbarang (peralatan) yang jarang dipakai tersebut di tempat yang sama).

d. Buatlah tanda yang menunjukkan tempat penyimpanan yaitu dapat diuraikan sebagai berikut:

- Perlu membuat tanda yang menunjukkan adanya tempat penyimpanan. 
- Tanda tempat penyimpanan dapat dibagi menjadi 2 kategori (secara teknis kedua bagian ini penting). Kategori pertama tanda lokasi dan yang kedua adalah label peralatan.

- Perlu adanya membutuhkan label

e. Barang-barang (peralatan) yang telah disimpan juga harus diberi label.

f. Di mana barang-barang (peralatan) itu terletak seharusnya terdapat dalam tabel meliputi kegiatan : Lokasi rak perlu dicatat dalam tabel adapun kegiatan tersebut dapat dibedakan dengan melakukan aktifitas yaitu : 1) Untuk membedakan secara tepat suatu lokasi untuk menyimpan apa, yaitu dengan mendaftar barangbarang (peralatan) apa saja yang ada pada rak di dalam tabel sesuai dengan jenis produk dan proses produksi., 2). Salah seorang teman dibawa ke sebuah rumah sakit untuk mendapatkan perlakuan medis. Jika ada orang mengunjunginya maka ia akan mencatat nama rumah sakit, tempat dan nomor kamar pasien sehingga siapa saja dapat dengan mudah mengunjunginya di kamar yang tepat. 3) Kebutuhan yaitu : jika terdaftar dalam format tabel, walaupun tanpa penjelasan yang lengkap masih dapat mudah mencari dan memperoleh apa yang dibutuhkan. 4) Cara menampilkan dengan benar yaitu : kapan saja perlu mengambil barang-barang (peralatan) yang diperlukan dari berbagai tempat untuk digunakan, maka dapat menghemat waktu jika mengikuti urutan yang ditunjukkan dalam tabel tersebut. Oleh karena itu tampilannya harus mudah dikenali sehingga dapat menghemat banyak waktu pencarian suatu barangbarang (peralatan).

g. Pemeriksaan, pemberian label, penyimpanan kembali di tempatnya untuk mempertahankan kondisi normal.

\section{KERANGKA KONSEP PENELITIAN}

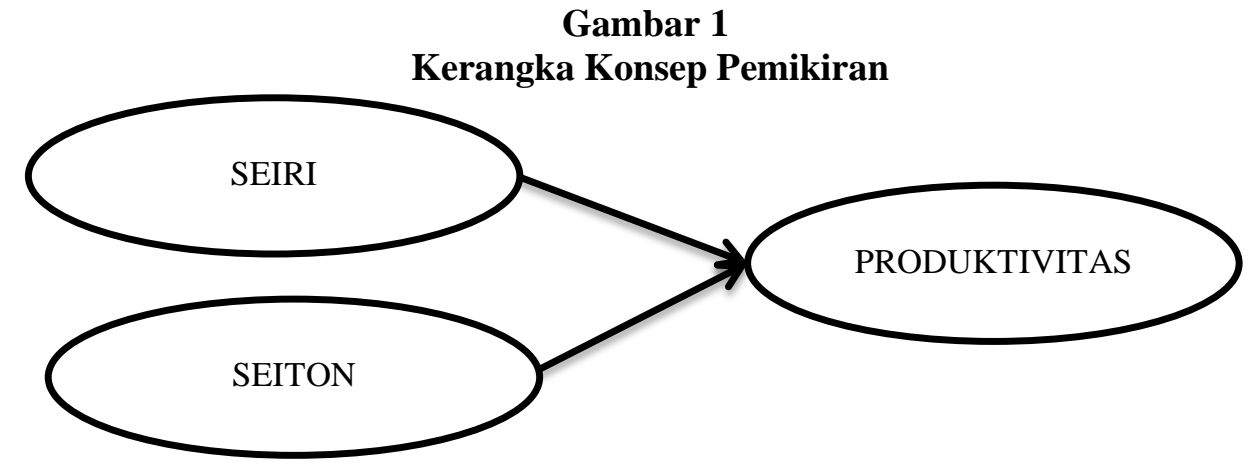




\section{Pernyataan Hipotesis}

$\mathrm{H}_{1}$ : Budaya 5R Seiri mempunyai pengaruh signifikan terhadap produktivitas kerja pada karyawan R\&D PT.HIT.

$\mathrm{H}_{2}$ : Budaya 5R Seiton mempunyai pengaruh signifikan terhadap produktivitas kerja pada karyawan R\&D PT.HIT.

\section{METODE PENELITIAN}

\section{Populasi dan Sampel Penelitian}

Populasi sasaran dalam penelitian ini adalah seluruh karyawan R\&D PT. Hartono istana Teknologi sebanyak 465 karyawan.

Tabel 3 Jumlah Karyawan R\&D PT. Hartono istana Teknologi

\begin{tabular}{|c|c|c|c|}
\hline BAGIAN & JML KARYAWAN & BAGIAN & JML KARYAWAN \\
\hline DQA & 57 & DATA & 41 \\
\hline MQA-MATAP & 25 & PCB & 19 \\
\hline SOFTWARE & 30 & AUDIO & 28 \\
\hline VIDEO & 36 & AUTRANS & 25 \\
\hline ADM & 7 & MICHANIC \& PROTOTYPE & 81 \\
\hline 31 & 13 & INDUSTRY DESIGN & 38 \\
\hline CNC & 7 & WHITEGOODS & 43 \\
\hline COST CONTROL & 15 & & \\
\hline \multicolumn{3}{|r|}{ Total } & 465 \\
\hline
\end{tabular}

pengambilan sampel berdasarkan pertimbangan tertentu atau pemilihan sekelompok subjek didasarkan atas ciri-ciri tertentu yang dipandang mempunyai sangkut paut yang erat dengan ciri-ciri populasi (Sugiyono, 2014:84-85). Pertimbangan yang dipakai dalam menentukan sampel penelitian ini adalah :

1. Responden adalah karyawan yang memiliki masa kerja minimal 2 tahun.

Maka pengambilan sampel dilakukan dengan rumus Slovin, dimana rumus ini tentu mempersyaratkan anggota populasi diketahui jumlahnya (N). Adapun pengambilan sampel dilakukan dengan rumus slovin menurut Sugiyono (2013:87) dengan batas toleransi kesalahan sebesar $10 \%$ sebagai berikut:

$$
\begin{aligned}
& n=\frac{N}{1+\mathrm{Ne}^{2}} \\
& n=\frac{465}{1+465(10 \%)^{2}} \\
& n=\frac{465}{5.65} \\
& n=82.3 \text { dibulatkan menjadi } 82 \text { responden. }
\end{aligned}
$$


Tabel 4: Proportionate Stratified Random Sampling

\begin{tabular}{|l|c|c|}
\hline BAGIAN & JUMLAH KARYAWAN & SAMPEL \\
\hline DQA & 57 & 10 \\
\hline MQA-MATAP & 25 & 4 \\
\hline SOFTWARE & 30 & 5 \\
\hline VIDEO & 36 & 6 \\
\hline ADM & 7 & 1 \\
\hline 3I & 13 & 2 \\
\hline CNC & 7 & 1 \\
\hline COST CONTROL & 15 & 3 \\
\hline DATA & 41 & 7 \\
\hline PCB & 19 & 3 \\
\hline AUDIO & 28 & 5 \\
\hline AUTRANS & 25 & 4 \\
\hline MICHANIC \& PROTOTYPE & 81 & 14 \\
\hline INDUSTRY DESIGN & 38 & 7 \\
\hline WHITEGOODS & 43 & 8 \\
\hline TOTAL & 465 & 82 \\
\hline
\end{tabular}

\section{Metode Pengumpulan Data}

Teknik pengumpulan data menggunakan kuesioner untuk mendapatkan data kuantitatif. Pengujian ini menggunakan teknik analisis regresi linier berganda dengan program SPSS versi 22.

Variabel dan indikator pada penelitian ini adalah (1). Seiri/ringkas dengan indikator memilah dokumen/katalog dan material yang digunakan dan tidak digunakan, memilah dokumen/katalog dan material yang sering digunakan dan jarang, melakukan pelabelan terhadap barang-barang dengan status on prose, membuang sampah dan barang-barang yang sudah tidak digunakan lagi. (2). Seiton/rapi dengan indikator dokumen/katalog tertata rapi dimeja maupun rak sesuai dengan label/penanda, alat tulis dan perlengkapan lainnya tertata rapi atau pada tempatnya, material/bahan sudah tertata dan terkelompokan dengan baik/pada tempatnya, instalasi listrik/kabel tertata rapi, semua alat ukur dan tools yang tidak digunakan berada pada tempatnya. (3). Produktivitas kerja dengan indikator mampu menyelesaikan pekerjaan dengan tepat waktu, melakukan perbaikan terus-menerus, nyaman dan mempunyai semangat yang tinggi, mutu dan kualitas pekerjaan. 


\section{HASIL DAN PEMBAHASAN}

Uji Validitas

Tabel 5: Hasil Pengujian Validitas Data

\begin{tabular}{|l|c|c|c|}
\hline \multicolumn{1}{|c|}{ Variabel } & Pearson Correlation & $\boldsymbol{r}_{\text {tabel }}$ & Status \\
\hline Seiri / Ringkas (X) $\left(\mathbf{X}_{1}\right)$ & 0.214 & Valid \\
\hline X1_1 & 0.868 & 0.214 & Valid \\
\hline X1_2 & 0.629 & 0.214 & Valid \\
\hline X1_3 & 0.788 & 0.214 & Valid \\
\hline X1_4 & 0.762 & 0.214 & Valid \\
\hline Seiton / Rapi (X_) & 0.885 & 0.214 & Valid \\
\hline X2_1 & 0.828 & 0.214 & Valid \\
\hline X2_2 & 0.722 & 0.214 & Valid \\
\hline X2_3 & 0.797 & 0.214 & Valid \\
\hline X2_4 & \multicolumn{3}{|l|}{} \\
\hline X2_5 & 0.865 & 0.214 & Valid \\
\hline Produktivitas Kerja (Y) & 0.934 & 0.214 & Valid \\
\hline Y_1 & 0.802 & 0.214 & Valid \\
\hline Y_2 & 0.894 & 0.214 & Valid \\
\hline Y_3 &
\end{tabular}

Sumber: data primer diolah, 2019

Berdasarkan tabel diatas adalah nilai Pearson Correlation dari masing-masing variabel penelitian. Hasil uji validitas data menunjukkan Pearson Correlation lebih besar dari $r_{\text {tabel }}$ atau 0.214, sehingga semua item atau indikator instrumen yaitu seiri, seiton, dan produktivitas kerja adalah valid dan dapat digunakan untuk pengukuran.

\section{Uji Reliabelitas}

Uji reliabilitas dalam penelitian ini menggunakan metode Cronbach's alpha dengan batasan 0,6 sebagai koefisien reliabilitas

Tabel 6: Hasil Pengujian Reliabelitas

\begin{tabular}{|l|c|c|}
\hline \multicolumn{1}{|c|}{ Variabel penelitian } & Cronbach's coefficient alpha & Ketarangan \\
\hline Seiri/Ringkas $\left(\mathrm{X}_{1}\right)$ & 0,800 & Reliabel \\
\hline Seiton/Rapi $\left(\mathrm{X}_{2}\right)$ & 0,855 & Reliabel \\
\hline Produktivitas Kerja $(\mathrm{Y})$ & 0,897 & Reliabel \\
\hline
\end{tabular}

Sumber: data primer diolah, 2019 
Berdasarkan hasil uji reliabilitas diatas, menunjukkan bahwa semua variabel seiri, seiton, dan produktivitas kerja mempunyai nilai Cronbach's coefficient alpha yaitu diatas 0,6 sehingga dapat dikatakan semua konsep pengukur masing-masing variabel dari kuesioner adalah reliable

\section{Uji Normalitas}

Tabel 7 : Hasil Uji Normalitas

One-Sample Kolmogorov-Smirnov Test

\begin{tabular}{|ll|r|}
\hline & & \multicolumn{1}{|c|}{$\begin{array}{c}\text { Unstandardized } \\
\text { Residual }\end{array}$} \\
\hline $\mathrm{N}$ & 82 \\
Normal Parameters & $\mathrm{a}, \mathrm{b}$ & Mean \\
& Std. Deviation & .0000000 \\
Most Extreme & Absolute & 2.43896609 \\
\cline { 2 - 3 } Differences & Positive & .051 \\
& Negative & .038 \\
& & -.051 \\
Test Statistic & .051 \\
Asymp. Sig. (2-tailed) & & $.200^{\mathrm{c}, \mathrm{d}}$ \\
\hline
\end{tabular}

a. Test distribution is Normal.

b. Calculated from data.

c. Lilliefors Significance Correction.

d. This is a lower bound of the true significance.

Hasil Uji normalitas dilakukan dengan uji Kolmogorov-Smirnov $(K S)$ pada variabel seiri, seiton terhadap produktivitas kerja di peroleh hasil nilai Asymp. Sig sebesar 0.200. Nilai uji normalitas yaitu signifikansi (Asymp. Sig.) $0.200>0.05$, berarti bahwa data dari seiri, seiton terhadap produktivitas kerja berdistribusi normal, sehingga layak untuk dilakukan penelitian selanjutnya.

\section{Uji Korelasi}

\section{Tabel 8 : Hasil Uji Korelasi}

\begin{tabular}{|ll|r|r|r|}
\hline \multicolumn{2}{|c|}{ Correlations } \\
\hline 5r seiri & 5r seiri & 5r seiton & produktivitas kerja \\
& Pearson Correlation & 1 & $.824^{\prime \prime}$ & $.592^{\prime \prime}$ \\
& Sig. (2-tailed) & & .000 & .000 \\
& $\mathrm{~N}$ & 82 & 82 & 82 \\
\hline 5r seiton & Pearson Correlation & $.824^{\prime \prime}$ & 1 & $.603^{\prime \prime}$ \\
& Sig. (2-tailed) & .000 & & .000 \\
& $\mathrm{~N}$ & 82 & 82 & 82 \\
\hline produktivitas kerja & Pearson Correlation & .592 & $.603^{\prime \prime}$ & 1 \\
& Sig. (2-tailed) & .000 & .000 & 82 \\
& $\mathrm{~N}$ & 82 & 82 & \\
& & &
\end{tabular}

\footnotetext{
${ }^{* \star}$. Correlation is significant at the 0.01 level (2-tailed).
} 
Dari tabel diatas diketahui :

1. Nilai Sig. (2-tailed) antara Seiri dengan produktivitas kerja adalah $0.000<$ 0.05 dan nilai Pearson Correlation adalah $0.592>\mathrm{r}$ tabel 0.214, maka dapat di simpulkan bahwa ada hubungan atau korelasi antara seiri dengan produktivitas kerja dan hubungan keduanya bersifat positif.

2. Nilai Sig. (2-tailed) antara Seiton dengan produktivitas kerja adalah 0.000 $<0.05$ dan nilai Pearson Correlation adalah $0.603>\mathrm{r}$ tabel 0.214, maka dapat di simpulkan bahwa ada hubungan atau korelasi antara seiton dengan produktivitas kerja dan hubungan keduanya bersifat positif.

\section{Uji Regresi Linier Berganda}

Tabel 9 : Hasil Uji Regresi Linier Berganda

\begin{tabular}{|c|c|c|c|c|c|c|}
\hline \multicolumn{7}{|c|}{ Coefficients $^{a}$} \\
\hline \multirow{2}{*}{\multicolumn{2}{|c|}{ Model }} & \multicolumn{2}{|c|}{ Unstandardized Coefficients } & $\begin{array}{l}\text { Standardized } \\
\text { Coefficients }\end{array}$ & \multirow[b]{2}{*}{$t$} & \multirow[b]{2}{*}{ Sig. } \\
\hline & & $\mathrm{B}$ & Std. Error & Beta & & \\
\hline \multirow[t]{3}{*}{1} & (Constant) & 5.448 & 1.568 & & 3.474 & .001 \\
\hline & $5 r$ seiri & .321 & .168 & .296 & 1.913 & .059 \\
\hline & $5 r$ seiton & .296 & .128 & .359 & 2.320 & .023 \\
\hline
\end{tabular}

a. Dependent Variable: produktivitas kerja

Dari tabel diatas diketahui :

1. Hipotesis 1

Seiri terhadap produktivitas kerja menghasilkan nilai $t_{\text {hitung }}$ sebesar $1.913<$ $t_{\text {tabel }} 1.989$ atau signifikansi $0.059>(0.05)$, maka daerah $\mathrm{H}_{0}$ diterima dan Ha ditolak, yaitu seiri atau ringkas tidak berpengaruh signifikan terhadap produktivitas kerja.

2. Hipotesis 2

Seiton terhadap produktivitas kerja menghasilkan nilai $t_{\text {hitung }}$ sebesar 2.320 $>t_{\text {tabel }} 1.989$ atau signifikansi $0.023<(0.05)$, maka daerah $\mathrm{H}_{0}$ ditolak dan Ha diterima, yaitu seiton atau rapi berpengaruh signifikan terhadap produktivitas kerja. 


\section{Pembahasan}

1. Seiri terhadap produktivitas kerja menunjukkan bahwa seiri atau ringkas tidak berpengaruh signifikan terhadap produktivitas kerja. Berdasarkan temuan lapangan bahwa 5R dengan Ringkas atau memilah barang yang digunakan dan tidak digunakan adalah belum optimal atau belum mampu memberikan kontribusi terhadap produktivitas, karena sebagian karyawan menyatakan bahwa dengan adanya ringkas barang-barang mereka pada hilang dan menjadikan tidak efektif. Hal ini ditemukan juga bahwa karyawan melakukan ringkas atau pemilahan barang yang dibutuhkan dan tidak dibutuhkan hanya asal-asalan tidak berdasarkan pertimbangan, jadi banyak resiko barangbarangnya pada hilang.

2. Seiton terhadap produktivitas kerja menunjukkan bahwa seiton atau rapi berpengaruh signifikan terhadap produktivitas kerja. Berdasarkan temuan lapangan bahwa 5R dengan rapi menata atau menempatkan barang-barang pada tempatnya, melabeli mempunyai kontribusi terhadap efektivitas pada saat kerja pada karyawan HIT.

\section{DAFTAR PUSTAKA}

Kartika, Hayu, Tri Hastuti. Analisa Pengaruh Sikap Kerja 5s Dan Faktor Penghambat Penerapan 5s Terhadap Efektivitas Kerja Departemen Produksi Di Perusahaan Sepatu.Jurnal Ilmiah PASTI Volume V Edisi 1 - ISSN 2085-5869, hal. 47-54.

Radi, Lucky Rinandiyana, Yanyan Sumaryana. 2015. Pengaruh Konsep 5s Terhadap Produktivitas Karyawan. Jurnal Ekonomi Manajemen Volume 1 Nomor 1, ISSN 2477-2275, hal.22-28.

Sartono, Dwi, Mukhamad Abduh. 2012. Pengaruh Program 5r (Ringkas, Rapi, Resik, Rawat, Rajin) Terhadap Produktivitas Kerja Karyawan Pada Produksi Pemintalan Benang. Jurnal Universitas Esa Unggul, hal 1-13.

Sugiyono. 2013. Metode Penelitian Pendidikan Pendekatan Kualitatif, Kuantitatif, dan $R \& D$. Bandung: Alfabeta.

Sugiyono. 2014. Metode Penelitian Kuantitatif, Kualitatif Dan R\&D. Bandung: Alfabeta.

Supriyanto, Agus. 2014. Pengaruh Sikap Kerja 5S (Seiri, Seiton, Seiso, Seiketsu, Shitsuke) Terhadap Produktivitas. Riset Manajemen \& Akuntansi Volume 5 Nomor 9, hal. 23-31.

Sutrisno, Edy. 2016. Manajemen Sumber Daya Manusia. Jakarta: Kencana

Veres, Cristina, Liviu Marian, Sorina Moica, Karam Al-Akel. 2018. Case study concerning 5S method impact in an automotive company. ScienceDirect Procedia Manufacturing 22, p.900-905.

Wahyudi. Penerapan Budaya Kerja 5S Dan Pengaruhnya Terhadap Kinerja Karyawan. Teknoterap Vol.1 No. 1, ISSN 2597-7679, hal. 49-71. 